\title{
Naturalizing the contributory
}

\author{
Philip Fox ${ }^{1}$ (D)
}

Received: 7 July 2020 / Accepted: 1 February 2021 / Published online: 15 February 2021

(C) The Author(s) 2021, corrected publication 2021

\begin{abstract}
This paper has two aims. First, I critically discuss Daniel Whiting's (Philos Stud 195(9):2191-2208, 2018) recent proposal that a reason to $\phi$ is evidence of a respect in which it is right to $\phi$. I raise two objections against this view: (i) it is subject to a modified version of Eva Schmidt's (Ethics 127(3):708-718, 2018) counterexample against the influential account of reasons in terms of evidence and 'ought', and-setting aside judgments about specific cases-, (ii) it is also in an important sense uninformative. Interestingly, it turns out that this last objection cannot be helpfully understood in terms of circularity. This leads to a more general question about the criteria of adequacy for reductive accounts of reasons: In what sense, if any, should such accounts be informative? The second aim of this paper is to clarify one such sense, which is suggested by reflection on Whiting's proposal. In particular, I argue that successful reductive accounts naturalize the contributory-by which I mean, roughly, that they explain the specifically contributory nature of reasons in fully non-normative terms. Moreover, I explain how views that fail this criterion are unable to meet certain key explanatory desiderata for reductive accounts of reasons. After broaching some of the wider implications for the project of understanding the notion of a reason in other terms, I conclude that the notion of naturalizing the contributory is a helpful notion for structuring the debate over reductive accounts of reasons.
\end{abstract}

Keywords Reasons - Evidence $\cdot$ Contributory $\cdot$ Rightness in a respect . Reductivism $\cdot$ Normativity

Philip Fox

philip.fox@hu-berlin.de

1 Institut für Philosophie, Humboldt-University Berlin, Unter den Linden 6, 10117 Berlin, Germany 


\section{Introduction}

There has been a burgeoning literature in recent years on reductive accounts of normative reasons. ${ }^{1}$ This literature includes both the intramural debate between proponents of various different reductive accounts (e.g. in terms of evidence, premises of good reasoning, good bases, or explanation) and the more general debate between reductivists on the one hand and reasons primitivists on the other, who think that the notion of a reason is in principle unanalyzable. ${ }^{2}$

However, one question that has received relatively little attention in this debate is what we want from an account of normative reasons in the first place, or what its criteria of adequacy are. This paper is meant to be a contribution to this question. One of my central claims will be that we should expect successful accounts of reasons to naturalize the contributory - by which I mean, roughly, that they explain the specifically contributory nature of normative reasons in fully non-normative terms. This criterion follows naturally from reflection on recent examples from the literature and helps to clarify the widespread idea that accounts of reasons should be in some important sense informative. More generally, I take the notion of naturalizing the contributory to be a useful novel concept for structuring the assessment of various accounts of reasons.

It makes sense to pause briefly here for a preliminary point about how I understand the term 'normative'. Readers will be aware that trying to say anything precise about this will immediately get us into difficult and controversial territory. The best approach for present purposes, it seems to me, is to follow a popular suggestion and define the normative simply in terms of a range of certain paradigmatic concepts (cf. Fumerton 2001; Schroeder 2015). On this approach, the normative includes notions like reason, ought, permissibility, goodness, virtue, correctness and fittingness, and all other notions relevantly like them. They contrast with descriptive notions, whose function is not to assess or prescribe, but to describe things as they are. Since the descriptive notions are an extremely diverse lot-ranging from concepts in metaphysics and the natural or social sciences to those more firmly situated in everyday life-, I will simply refer to them as non-normative notions. Whether some or even

\footnotetext{
1 Two clarifications: First, I use the term 'reductive' broadly for all views according to which the notion of a reason can be helpfully explained in other terms; these 'other terms' need not themselves be fully non-normative. Second, and as has become customary in this debate, I will not pay much attention to the distinction between providing a real definition of normative reasons and providing an analysis of the concept of a normative reason. Speaking of 'accounts' of normative reasons is meant to be neutral on that score.

${ }^{2}$ For the view that reasons are evidence of some sort, see Kearns and Star (2008, 2009, 2011, 2013a, b, 2015; see also Star 2011, 2015, 2016), Sharadin (2016), Smith (2018), Thomson (2008) and (arguably) Silverstein (2016). For the view that reasons are premises of good reasoning, see Asarnow (2016, 2017), Hieronymi (2005, forthcoming), McHugh (2012), McHugh and Way (2016, 2018a, b), Paakkunainen (2017), Raz (1978, 1999), Setiya (2007, 2014) and Way (2017). For the view that reasons are good bases, see Gregory (2016). For the view that reasons are explanations of some sort, see Broome (2004, 2008, 2013, 2015, 2018), Finlay (2006, 2012, 2014), Schroeder (2007), Raz (1999) and Toulmin (1950). For the view that reasons are in principle unanalyzable, see Dancy (2004), Scanlon (1998, 2014), Skorupski (2010) and Parfit (2011).
} 
all normative notions can be reduced to non-normative notions is not a question that I will discuss here. What matters for our purposes is just that we have some intuitive way of distinguishing the two.

Let us return to the main theme. For the most part, my argument will be developed around an illustrative test case, viz. Daniel Whiting's (2018) recent proposal that a reason to $\phi$ is evidence of a respect in which it is right to $\phi$. This view serves not just as a useful example for my argument, but also merits discussion on independent grounds. As I will explain in more detail below, it promises to avoid at least two serious counterexamples to the influential, and in many ways tempting, account of reasons in terms of evidence and 'ought' proposed by Judith Thomson, Stephen Kearns and Daniel Star. Hence, a further aim of this paper is to contribute to an assessment of Whiting's independently interesting account of reasons.

I proceed as follows. Section 2 begins with some relevant background on evidential accounts of reasons. In particular, I introduce two important counterexamples, based respectively on so-called 'counter-evidential' and 'redundant' reasons, against the account of reasons in terms of evidence and 'ought'. Section 3 briefly motivates Whiting's modification of this account, by explaining how it manages to avoid these counterexamples. In Sect. 4, I put forward the first of two objections against Whiting's view: as I will argue, it is still subject to a modified version of Eva Schmidt's (2018) counterexample against the original Thomson/Kearns and Star account.

Section 5 sets aside judgments about specific cases and turns to a second, more general objection. This objection is based on the suspicion that Whiting's view is in some important sense uninformative: at least on the face of it, the notion of rightness in a respect just seems very close to the notion of a reason. However, it turns out that the most straightforward way to develop this suspicion-viz., in terms of circularity-is unpromising, since we do seem to have an independent grip on the notion of rightness in a respect. I then explain how a more plausible version of this objection can be developed if we rely on the notion of naturalizing the contributory, a notion that also has wider consequences for the debate over reductivism about reasons.

More specifically, I consider the structure of various prominent accounts of reasons and argue that a view like Whiting's is inferior, not because it is circular or free of any content, but because it tries to explain the specifically contributory nature of normative reasons in terms that are themselves normative and contributory. Section 6 explains how this robs the view of the kind of explanatory power that we want from reductive accounts and draws some more general conclusions for the project of understanding the notion of a reason in other terms. Section 7 concludes.

\section{Evidential accounts of reasons: some background}

\subsection{Two evidential accounts: $R=E O$ and $R=E R R$}

The paradigmatic evidential account has been proposed independently by Judith Thomson and Stephen Kearns and Daniel Star: 
$(\mathrm{R}=\mathrm{EO})$ The fact that $p$ is a reason for a person to $\phi$ if and only if $p$ is evidence that this person ought to $\phi$.

As has often been noted, $\mathrm{R}=\mathrm{EO}$ is in many ways an attractive view. It promises a unified account of reasons for action, belief and affective attitudes, it helps to explain why rational agents care about their reasons in ordinary contexts of normative deliberation and advice, and it offers a straightforward explanation of the weight of reasons in terms of the weight of evidence (see, e.g., Kearns and Star 2009).

At the same time, $\mathrm{R}=\mathrm{EO}$ has been subjected to a range of serious counterexamples. Before I introduce these counterexamples, however, I will first present Whiting's recent modification of $\mathrm{R}=\mathrm{EO}$. Having clarified the central aspects of Whiting's suggestion, I will then explain how each of the two evidential accounts deals (or fails to deal) with certain problem cases that have been raised for $\mathrm{R}=\mathrm{EO}$. Whiting $(2191)^{3}$ states his view as follows:

$(\mathrm{R}=\mathrm{ERR})$ The fact that $p$ is a reason for a person to $\phi$ if and only if:

$R$ is a respect in which it is right for that person to $\phi$; and the fact that $p$ is evidence of $R$.

Here is an example to illustrate this view. That the panorama on the peak of Mont Blanc is extraordinary is evidence that you will enjoy climbing it. That you will enjoy climbing it is a respect in which it is right for you to climb it. Hence, that the panorama on the peak of Mont Blanc is extraordinary is a reason for you to climb it.

Let me now turn to a number of clarifications that will be important later on. First, note that $\mathrm{R}=\mathrm{ERR}$ does not speak explicitly about reasons against doing something. But, presumably, we can say something like the following on its behalf. That the trail is dangerous is evidence that you will hurt yourself if you climb. That you will hurt yourself if you climb is a respect in which it is wrong for you to climb. Hence, that the trail is dangerous is a reason for you not to climb. What it is right for you to do, all things considered, then depends on how these different reasons weigh against each other. (I say more about the weight of reasons in Sect. 5.)

Second, some comments about rightness. Most importantly, the notion of rightness is an overall notion: judging a response to be right is not merely to judge it right in this or that respect, but rather to judge it as right as such (2195). Moreover, the notion of rightness can be applied to various different responses, including actions, beliefs and affective attitudes like fear or admiration (2199). Finally, Whiting (2194) tells us that his notion of rightness is the same as Richard Chappell's (2012) and Conor McHugh and Jonathan Way's (2016) notion of fittingness. ${ }^{4}$ One implication of this is that rightness, so understood, is what I will call a slack notion: it readily allows for cases where it is right to $\phi$ and right not to $\phi$-for example, it may be both right for you to play a game of tennis this afternoon and right not to (2194).

\footnotetext{
3 This and all subsequent references to Whiting's work refer to the relevant pages in Whiting (2018).

4 This actually raises a number of further questions, including questions about what exactly it means to say that an action (as opposed to an attitude) is fitting and about the nature of the underlying standards of fittingness. However, pursuing these questions would lead us too far afield.
} 
It thereby contrasts with strict notions like 'ought', which do not readily allow for conflicts.

Third, unlike rightness, the notion of rightness in a respect is a contributory notion (2198). More specifically, a respect in which some response is right is a fact in virtue of which that response is right "in some way or regard," or a fact that makes that response right "in some way or regard" (2195). A natural further question is what it means for a fact to make a response right "in some way or regard." For a moment, let us keep this notion on an intuitive level: for example, that the restaurant around the corner serves delicious food is a respect in which it is right to go there, because it is a fact in virtue of which going there is right in some way (even if it happens to be wrong overall). ${ }^{5}$ Importantly, while a respect in which a response is right might itself be a reason for that response, Whiting (2195) claims that the notion of rightness in a respect is not identical to the notion of a reason. For example, while the fact that the alarm is sounding is a reason to leave the building, it is not a respect in which it is right to do so (rather, it is evidence of such a respect).

Fourth, proponents of $\mathrm{R}=\mathrm{ERR}$ can remain relatively neutral about how the notion of evidence should be understood. Any account that captures the intuitive idea that evidence is something that indicates or makes it more likely that some fact obtains or that some proposition is true will do. The only constraint is, obviously, that the notion of evidence must not itself be understood in terms of normative reasons, on pain of circularity (cf. Whiting 2205f).

Since this is not entirely uncontroversial and will be important later on, let me briefly dwell on this point. Throughout this paper, I will assume that reductivists can avail themselves of a fully non-normative notion of evidence. Some people deny that there is such a notion, usually because they think that the relevant notion of evidence for some proposition just is the notion of a reason to believe that proposition (cf. Kelly 2007). I lack the space to discuss the arguments for that view in detail, but I also think that, once we draw some relevant distinctions, the claim that evidence is a non-normative notion, suitably clarified, should anyway strike us as a very natural position. ${ }^{6}$

One such distinction, adapting a point by Schroeder (2015), is between saying that evidence is normatively important and that evidence is itself a normative notion. No reductivist needs to deny that evidence is normatively important, in the sense that there being evidence for some proposition provides reasons to believe that proposition, or makes it the case that such reasons obtain. But that is a far cry from

\footnotetext{
5 Perhaps it is less natural to speak of respects of rightness in the case of attitudes like belief, fear or admiration. Presumably, this is because there seems to be only one respect in which each of these attitudes can be right: the only respect in which a belief can be right is that the believed proposition is true, the only respect in which fear can be right is that the feared object is dangerous, the only respect in which admiration can be right is that the admired object is admirable, etc. In that case, $R=E R R$ correctly predicts that only evidence bearing on, respectively, truth, dangerousness, admirability etc. is a reason for these attitudes. Suppose, however, you think that there are indeed several respects in which an attitude like belief can be right: say, that it is true and that it is useful. Then you presumably also think that evidence for the usefulness of a belief is a reason for that belief, in which case $R=E R R$ again predicts the correct result.

${ }^{6}$ For a similar recent treatment, see Hofmann (forthcoming).
} 
saying that the notion of evidence is itself normative. (Compare: even if there being food in the kitchen provides reasons to go there, it does not follow that 'food' is a normative notion.) Similarly, the evidential fact that some proposition $p$ is evidence for another proposition $q$ might well help to ground or explain the normative fact that $p$ is a reason to believe $q$. But, to me at least, there still seems to be a clear sense in which these two facts are not identical: the one is a purely descriptive fact about the relevant evidential relationship, the other is a fact about the normative import of that relationship.

In order to be able to draw these distinctions, it makes sense to keep apart the notion of evidence and the notion of a reason, just like it makes sense to keep apart facts about the evidence and facts about the normative import of the evidence. Moreover, these distinctions explain why, pace Kelly (2007), there is really nothing paradoxical or incoherent about the claim 'I have overwhelming evidence for $p$, but no reason to believe that $p$-epistemic error theorists who reject the notion of an epistemic reason on metaphysical grounds might well assert such a claim, precisely because their meta-normative convictions give them little reason to deny the existence of evidential relationships. Of course, the epistemic error theory might be substantively mistaken, but it seems to be a view that can at least be coherently stated-which brings us back to the assumption that there is a perfectly coherent, non-normative notion of evidence for such purposes. Finally, that assumption can also be motivated on purely dialectical grounds: my own argument is premised on the idea that views like $\mathrm{R}=\mathrm{EO}$ are paradigmatically informative accounts of reasons, and attempts to clarify the intuitive sense in which it is more informative than $\mathrm{R}=\mathrm{ERR}$. That picture requires that the notion of evidence does not collapse into the notion of a reason, since otherwise $\mathrm{R}=\mathrm{EO}$ itself would be flatly circular - an impression which, as far as I can see, is not very common in the literature. So even if we cannot fully resolve these issues here, I will treat the idea that there is a fully non-normative notion of evidence as a reasonable assumption for present purposes.

\subsection{The counterexamples: counter-evidential and redundant reasons}

We can now turn to the counterexamples and ask how each of the two evidential accounts deals with the relevant cases. Here, I focus on what I take to be two particularly serious counterexamples directed specifically against $\mathrm{R}=\mathrm{EO}$. The first type of cases involves what John Brunero (2009, 2018; see also McKeever and Ridge 2012) calls counter-evidential reasons. A revised version of Brunero's example goes as follows. (I take it that, unlike Brunero's original example, my version is immune to the reply in Kearns and Star [2013a: 83], but I will not delve into these details here.)

(Movies) You and your friends plan to go to the movies tonight and it is your job to choose between the only two alternatives, $M_{1}$ and $M_{2}$. The fact that your friend Carla would enjoy $M_{1}$ is a reason for choosing it. But since it is also evidence that your friend Carlos will not enjoy it, it is at the same time a reason not to choose $M_{1}$ (and to choose $M_{2}$ instead). Since everyone's enjoyments count for the same, the two reasons provided by this fact are equally weighty. 
If $\mathrm{R}=\mathrm{EO}$ is true, then the fact that Carla would enjoy $M_{1}$ is a reason to choose $M_{1}$ only if it is evidence that you ought to choose $M_{1}$, and it is a reason not to choose $M_{l}$ only if it is evidence that you ought not to choose $M_{l}$. The problem for $\mathrm{R}=\mathrm{EO}$ is that this fact is evidence for neither of the two 'ought' claims. Hence, $\mathrm{R}=\mathrm{EO}$ fails to accommodate the intuitive verdict about this case.

To see why, note that the probabilities of the following three propositions must add to one: (i) you ought to choose $M_{1}$, (ii) you ought to choose $M_{2}$, (iii) it is not the case that you ought to choose $M_{1}$ and it is not the case that you ought to choose $M_{2}$ (i.e., you may choose either $M_{1}$ or $M_{2}$ ). The only way that the fact that Carla would enjoy $M_{1}$ could raise the probabilities of both (i) and (ii) —as it should, if $\mathrm{R}=\mathrm{EO}$ is to yield the intuitively correct verdict-is by lowering the probability of (iii). But it does not do that. In fact, it raises the probability of (iii): since the fact that Carla would enjoy $M_{1}$ provides a reason to choose $M_{1}$ that is of exactly the same weight as the reason that it provides to choose $M_{2}$, this fact is actually evidence that you may choose either $M_{1}$ or $M_{2}$.

More generally, it seems very plausible to think that, at least in this type of case, if some fact speaks in favor of two incompatible options without speaking more strongly in favor of one rather than the other, then this fact indicates that both choices are permissible. The fact that Carla would enjoy $M_{1}$ thus makes it more likely that (iii) is true and, hence, less likely that (i) and (ii) are true. Therefore, it is neither evidence that you ought to choose $M_{1}$ nor evidence that you ought to choose $M_{2}$, which is why $\mathrm{R}=\mathrm{EO}$ mistakenly predicts that it is neither a reason to choose $M_{1}$ nor a reason to choose $M_{2}$. This contradicts the highly plausible judgments that, if Carla would enjoy a certain movie, this is a reason to choose it, and that (insofar as it indicates that Carlos would not enjoy that movie) it is also a reason not to choose it.

In contrast, $\mathrm{R}=\mathrm{ERR}$ easily delivers the correct result in this type of case (cf. Whiting 2200f). Even if the fact that Carla would enjoy $M_{1}$ is neither evidence that you ought to choose it nor evidence that you ought not to choose it, it is clearly evidence of a respect in which it is right to choose it-say, that it will make Carla happy-and of a respect in which it is wrong to choose it-say, that it will make Carlos unhappy. It thereby predicts, correctly, that this fact is both a reason to choose $M_{1}$ and a reason not to choose $M_{1}$ (and to choose $M_{2}$ instead).

The second type of cases involves what Daniel Wodak (2019) calls redundant reasons. Here is an example:

(REWARD) The balance of your reasons makes it the case that you ought to $\phi$.

Now, the Gods tell you that, if you do whatever you ought to do, they will reward you with an eternity of pleasure in the afterlife.

It seems intuitively clear that the fact that the Gods will reward you with an eternity of pleasure in the afterlife is a reason for you to $\phi$ (cf. Wodak 2019: p. 3). This reason is 'redundant' in the sense that it obtains only if it is already, independently true that you ought to $\phi$. But, precisely because you first need to know which act you (independently) ought to perform before you can find out which action will be rewarded, the fact that you will be rewarded for $\phi$-ing can make no 
evidential contribution to the fact that you ought to $\phi$. Still, it clearly seems to be a reason to $\phi . \mathrm{R}=\mathrm{EO}$ mistakenly predicts that it is not. ${ }^{7}$

While Whiting himself does not discuss redundant reasons, his view again seems to deliver the correct result. Even if it is already, independently true that you ought to $\phi$, the fact that the Gods will reward you for $\phi$-ing might well be evidence for an additional respect in which $\phi$-ing is right, where $\phi$-ing was not right in that particular respect before. Hence, $\mathrm{R}=\mathrm{ERR}$ is compatible with the intuitive verdict that this fact is a reason.

Despite its many attractions, $\mathrm{R}=\mathrm{EO}$ thus seems to face compelling counterexamples. Here, I will not consider possible defensive strategies on behalf of $\mathrm{R}=\mathrm{EO}$. Instead, I will simply note that Whiting's modification easily accommodates the problematic cases. Together with the fact that it also promises to retain the other virtues of evidential accounts, this gives us all the more reason to pay careful attention to this view, which (unlike $\mathrm{R}=\mathrm{EO}$ ) has not yet been seriously discussed in the literature. (An additional reason, to which I turn later, is that it allows us to introduce the notion of 'naturalizing the contributory' and to clarify in what sense successful accounts of reasons are informative.) Since evidential accounts of reasons are generally attractive, modifying $\mathrm{R}=\mathrm{EO}$ in a way that makes it immune to these counterexamples would make it a particularly appealing view, assuming that it did not run into severe problems elsewhere. The next sections argue, however, that this is not so.

\section{A new counterexample against $R=E R R$}

This section argues that $\mathrm{R}=\mathrm{ERR}$ returns the wrong verdict in a certain type of case involving instrumental reasons. To see why, we need to slightly modify a counterexample to $\mathrm{R}=\mathrm{EO}$ due to Eva Schmidt (2018). A version of Schmidt's (2018: 713) original counterexample reads as follows:

(CAKE) You wake up in the morning and find yourself remembering that you ought to buy flour. From this you infer, via an inference to the best explanation, that you ought to bake a cake. (Given your evidence, this is the most plausible explanation of why you ought to buy flour.)

In CAKE, that you ought to buy flour (i.e., to take the necessary means to a certain end) is evidence that you ought to bake a cake (i.e., to realize that end). Hence, $\mathrm{R}=\mathrm{EO}$ predicts that the fact that you ought to buy flour is a reason for you to bake a cake. But that sounds wrong. If anything, the fact that you ought to bake a cake is a reason for you to buy flour; to claim the reverse, as $\mathrm{R}=\mathrm{EO}$ does, gets the order of explanation wrong. More generally, that you ought to realize a certain end may be a reason for you to take the necessary means, but that you ought to take the necessary means is not typically a reason to realize a certain end.

\footnotetext{
7 Note that, strictly speaking, I need not take a stand on whether either this or the previous counterexample succeeds against $\mathrm{R}=\mathrm{EO}$. The important point, as I explain below, is that even if they do, $\mathrm{R}=\mathrm{ERR}$ is off the hook.
} 
Arguably, the following slight modification works equally against $R=E R R$ :

$\left(\mathrm{CAKE}^{*}\right)$ You wake up in the morning and find yourself remembering that you ought to buy flour. From this you infer, via an inference to the best explanation, that you ought to bake a cake. (Given your evidence, this is the most plausible explanation of why you ought to buy flour.) You then infer from the fact that you ought to bake a cake, via another inference to the best explanation, that your cakes taste good. (Given your evidence, it would be very unlikely that you ought to bake a cake unless your cakes taste good.)

In $\mathrm{CAKE}^{*}$, that you ought to buy flour is not just (via the first inference) evidence that you ought to bake a cake, but also (via the second inference) evidence that your cakes taste good. That your cakes taste good is a respect in which it is right for you to bake a cake. Hence, $\mathrm{R}=\mathrm{ERR}$ predicts that the fact that you ought to buy flour is a reason for you to bake a cake. But that sounds wrong. If anything, the fact that you ought to bake a cake is a reason for you to buy flour; to claim the reverse, as $\mathrm{R}=\mathrm{ERR}$ does, again gets the order of explanation wrong.

Do proponents of $R=E R R$ have any resources to deal with this counterexample? I cannot think of any. On the one hand, $R=E R R$ clearly implies that the fact that you ought to buy flour is evidence of a respect in which baking a cake is right, and so is a reason to bake a cake. This is because it is hard to deny that the premises of an abductive inference provide evidence for its conclusion, on pain of accepting an extremely skeptical view on which evidential relations hold only across deductive inferences.

On the other hand, proponents of $\mathrm{R}=\mathrm{ERR}$ cannot plausibly bite the bullet and claim that the fact in question is a reason to bake a cake. Star $(2018$, p. 7) himself suggests such a strategy in a brief comment on Schmidt's original counterexample to his own view. With regard to the fact that one ought to take a certain means to one's end, he tells us that

this fact does count in favor in one sense: it's something that in some not unrealistic contexts it would be appropriate for [someone] to use as a guide in his reasoning when he is trying to work out what he ought to do ... I agree that the relevant fact does not count in favor in a stronger sense than this, but why should we think only things that do so are reasons? Perhaps we should, but we won't settle this question by appeal to intuitions about cases.

Moreover, Star (ibid.) suggests that this position is in good company:

It's worth noting in this context that Kieran Setiya and Jonathan Way defend accounts of reasons that give the reasoning guiding role of reasons an even more central place in explaining what reasons are: roughly speaking, they take reasons to be appropriate premises in pieces of good reasoning.

However, Star's reply is not very compelling. First, it is misleading to suggest that it gets support from the attractive idea that reasons are premises of good reasoning. To see why, note that at least one prominent development of this idea 
actually entails that the fact in question is not a reason. For, according to McHugh and Way (2016: p. 591f), premises of good reasoning are reasons for a response only if they figure in a good basic pattern of reasoning towards that response-by which they mean, roughly, a pattern that does not explicitly or implicitly rely on intermediate steps. Yet the very structure of the examples above makes clear that the relevant pattern of reasoning is not a basic, but a complex one. The intuitively good piece of reasoning is not'I ought to buy flour; so, I'll bake a cake', but rather the following one, which clearly involves an intermediate step: 'I ought to buy flour; so, I ought to bake a cake; so, I'll bake a cake'. ${ }^{8}$ This last pattern is a complex one: the first transition is an example of good theoretical reasoning, while the second transition is an example of good enkratic reasoning. Since the fact that you ought to buy flour does not figure in a good basic pattern of reasoning towards baking a cake (or perhaps an intention to do so), it is not, according to McHugh and Way's account, a reason to bake a cake. This, I think, is the correct result.

Second, it is also misleading to suggest that the force of the counterexample rests entirely on an "appeal to intuitions about cases." The verdict that the means-fact does not provide a reason to realize the end is not just intuitively strong, but also explained by the compelling general claim that normative support relations run from ends to means, rather than the other way around. To say that the relevant verdict is just a contested intuition about a particular case simply ignores that it also reflects a very plausible idea about the correct explanation of instrumental reasons, an explanation that runs from ends to means (and not vice versa).

Against this background, I conclude that $\mathrm{R}=\mathrm{ERR}$ lacks the resources to deal with this counterexample. One might think it was obvious that $R=E R R$ would be subject to this kind of counterexample, given its similarity to $\mathrm{R}=\mathrm{EO}$ and the fact that the counterexample was explicitly constructed to disprove $\mathrm{R}=\mathrm{EO}$. It is worth noting, however, that this was actually not obvious, for we have seen before that $R=E R R$ successfully avoids two other central counterexamples against $\mathrm{R}=\mathrm{EO}$.

\section{Is $\mathbf{R}=$ ERR informative?}

In the previous section, I have argued that $\mathrm{R}=\mathrm{ERR}$ is not extensionally adequate. The aim of this section is to develop a more general, structural criticism of the view (which, as I explain later, teaches an important lesson for the project of understanding normative reasons in other terms). To do so, I now return to the earlier observation that $\mathrm{R}=\mathrm{ERR}$ seems to be in an important sense uninformative-or at least less informative than other accounts of reasons, and so less informative than accounts of reasons could possibly be. ${ }^{9}$ One advantage of this criticism is that it would remain

\footnotetext{
${ }^{8}$ It does not matter for my argument whether it also contains an additional step from 'I ought to bake a cake' to 'My cakes taste good'. In order to show that the relevant pattern is not a basic one, it suffices to show that it involves at least one intermediate step.

${ }^{9}$ It is perhaps instructive in this context that when Whiting discusses what he calls $\mathrm{R}=\mathrm{MR}$, the view that a reason to $\phi$ is a fact that makes it right to $\phi$, he does not raise one of the more obvious objections to this view: viz., that the notion of a reason does not seem very different from the notion of a rightmaker. Note that Laura Schroeter and François Schroeter (2009), who defend the view that reasons are right-makers, explicitly deny that this offers us an informative account of normative reasons.
} 
effective even if one agreed with Star that counterexamples against evidential accounts inevitably rely on contested intuitions about specific cases.

The most straightforward way of developing this suspicion would be in terms of circularity. Perhaps Whiting's account implicitly relies on the notion of a reason, insofar as we have no independent grip on the notion of evidence or (in particular) the notion of rightness in respect-independent, that is, from the very notion of a normative reason.

However, I do not think that this line of argument is particularly promising. I have already explained why I think that there is a non-normative notion of evidence that does not implicitly rely on the notion of a reason. What is more, I am happy to grant that the same holds for the notion of rightness in a respect. To begin with, Whiting's notion of rightness as such does not seem to presuppose the notion of a reason. Whiting himself says that by 'rightness', he means what McHugh and Way (2016) mean by 'fittingness'. And when someone claims, for example, that beliefs are fitting just in case they are true, or that an intention to $\phi$ is fitting just in case $\phi$-ing is permissible, these are not themselves claims about reasons. ${ }^{10}$

Of course, one need not deny that there are constitutive connections between claims about fittingness and claims about reasons, just like there are surely constitutive connections between claims about reasons and claims about 'ought'. But no one has raised a circularity objection against $\mathrm{R}=\mathrm{EO}$ just because there are such connections. Moreover, those who still quibble with Whiting's notion of rightness as fittingness - for example, because they think that the notion does not apply naturally to actions as opposed to attitudes-could simply replace the notion of a respect in which it is right to $\phi$ by the notion of a respect in which one ought to $\phi$, without thereby significantly affecting the analysis. ${ }^{11}$ Again, the resulting account of reasons in terms of 'ought' would be an inappropriate target of circularity objections.

Perhaps most importantly, we also seem to have a clear intuitive grip on the distinction between the notion of a reason and the notion of rightness in a respect (or what one ought to do in a respect). For example, the fact that the alarm is sounding is a reason to leave the building, but it is not itself a respect in which it is right to leave the building - it is merely evidence of such a respect, such as the fact that if you do not leave the building, you are going to die (cf. Whiting 2195f). Whiting is free to rely on our independent grip on this notion of rightness in a respect and define the notion of a reason in terms of this primitive. No circularity objection seems to apply.

Having said all that, the observation that $\mathrm{R}=\mathrm{ERR}$ is not circular does not, as far as I can see, remove the suspicion that the view is in some sense uninformative, or

\footnotetext{
10 Plausibly, beliefs are fitting just in case they are true. When someone says that it would be fitting to believe some arbitrary truth, they are not thereby committing themselves to the claim that there is a reason to believe it. Similarly, when someone says that it would be fitting to scratch one's head now, they are not thereby committing themselves to the claim that there is a reason to do so; doing so might simply be permissible without there being any reason in favor of doing it.

11 At least, this suggests itself as an account of requiring reasons. How it could be extended to merely justifying reasons is a different question, but one that most accounts of reasons face.
} 
less informative than accounts of this kind could be. This suspicion will be the starting point for the subsequent discussion, which develops and generalizes it. Here is a way of getting at this suspicion on an intuitive level.

The notion of a reason is a contributory notion. To say that there is a reason for a response is not yet to make a verdict about the overall normative status of that response; rather, the existence of a reason merely contributes to such a status. In particular, the notion of a reason is the notion of something that can combine in various ways with other reasons to make it the case that some response is right, or that it ought to be given, or some such, where each reason makes its own contribution to that overall normative status. One thing that we want from an account of reasons is that it explains the nature of this contribution.

Now, the notion of rightness in a respect is also a contributory notion: to say that some response is right in a respect is not yet to make a verdict about its overall normative status, while different respects of rightness can each contribute to such a status. This means, however, that the relationship between respects of rightness and overall normative statuses is of the same kind as the relationship between reasons and overall normative statuses, in which case anyone who wants an account of the latter relationship will not be much helped by an account that presupposes an understanding of the former relationship (which is not itself explained by the account). What seems unhelpful about $\mathrm{R}=\mathrm{ERR}$ is that it wants to make sense of one kind of normative contribution (the contribution made by reasons) in terms of another kind of normative contribution (the contribution made by respects of rightness) that is just as worthy of explanation as the other.

I have now provided some intuitive support for the suspicion that $\mathrm{R}=\mathrm{ERR}$ is insufficiently informative, even if it is not strictly circular. To be sure, this does not amount to a full-blown defense, and the scope of my argument is limited by the fact that, if someone does not share this suspicion at all, much of the subsequent discussion might not speak to them. But since I expect many readers to be on board with the intuitive considerations just mentioned, this suspicion strikes me as an interesting and potentially fruitful starting point. In what follows, I will try to extract from it a general desideratum for accounts of reasons.

If $\mathrm{R}=\mathrm{ERR}$ is not circular, but it still seems uninformative in some interesting sense, this means that there must be a sense of being uninformative that is interestingly different from circularity. I will now try to isolate such a sense. To do so, I begin by considering two exemplary analyses of reasons that clearly are informative, offer a diagnosis of what makes them so, and then use this diagnosis to explain the sense in which $\mathrm{R}=\mathrm{ERR}$ is uninformative. I also discuss two other analyses where things are a bit less clear, drawing some further distinctions that will help to better understand the diagnosis in question. In the next section, I will then draw a number of more general conclusions for the project of understanding the notion of a reason in other terms.

Our first example is $\mathrm{R}=\mathrm{EO}$, which proceeds in terms of two central notions: 'evidence' and 'ought'. The notion of evidence is a non-normative notion, and it is a contributory notion in the sense that different pieces of evidence can combine in order to yield conclusions about which propositions are supported by the evidence all-things-considered. The notion of 'ought' is a normative notion, and it is an overall notion, because to say that one ought to $\phi$ is not merely to say that something 
counts in favor of $\phi$-ing in this or that respect, but that $\phi$-ing is the thing to do allthings-considered. Hence, $\mathrm{R}=\mathrm{EO}$ analyzes a contributory normative notion ('reason') in terms of a contributory non-normative notion ('evidence') and an overall normative notion ('ought'). If it is successful, then the way in which various evidential factors (non-normatively) determine which 'ought' propositions are most likely to be true given the evidence helps us to understand how various reasons (normatively) determine which 'ought' propositions are true. In particular, $\mathrm{R}=\mathrm{EO}$ promises a straightforward account of the (normative) weight of reasons in terms of the (non-normative) weight of evidence, thereby making sense of one important normative phenomenon in non-normative terms. (I return to this point later.)

The second example is Kieran Setiya's $(2007,2014)$ version of $\mathrm{R}=\mathrm{PGR}$, according to which reasons are premises of good reasoning. Setiya's view can be summarized as follows:

$(\mathrm{R}=\mathrm{PGR})$ The fact that $p$ is a reason for a person to $\phi$ if and only if that person has a collection of psychological states, $C$, such that she could be motivated to $\phi$ on the basis of good reasoning from $C$-and-the-belief-that- $p$ (and $C$ contains no false beliefs). ${ }^{12}$

While one could raise a lot of questions about how this view is to be understood in detail, I set those questions aside and focus instead on the following structural similarity with $\mathrm{R}=\mathrm{EO} . \mathrm{R}=\mathrm{PGR}$ proceeds in terms of two central notions: 'good reasoning' and 'motivation'. The notion of motivation is a non-normative notion, and it is contributory in the sense that agents can be motivated to do different things to different degrees, and what they will end up doing depends on how these different motivational factors combine. The notion of good reasoning is a normative notion, and it is an overall notion, because to say that a pattern of reasoning is good is not merely to say that it is good in this or that specific respect, but that it is good all-things-considered. Hence, like $\mathrm{R}=\mathrm{EO}, \mathrm{R}=\mathrm{PGR}$ analyzes a contributory normative notion ('reason') in terms of a contributory non-normative notion ('motivation') and an overall normative notion ('good reasoning'). If it is successful, then the way in which various motivational factors (non-normatively) determine what the wellreasoning agent will do helps us to understand how various reasons (normatively) determine what an agent ought to do. In particular, R=PGR promises a straightforward account of the (normative) weight of reasons in terms of the (psychological) weight of motivation in well-reasoning agents, thereby making sense of one important normative phenomenon in non-normative terms. ${ }^{13}$

\footnotetext{
12 Note that Setiya (2014: p. 223) himself defends only the biconditional, and remains neutral about the claim that reasons reduce to premises of good reasoning.

13 An interesting question is whether what I say about Setiya also holds for McHugh and Way's (2016, 2018a, b; see also Way 2017) version of R=PGR. I think that this might well be the case, but since their view is more complex and involves some issues that I cannot settle here, I can only suggest a very rough sketch.

Simplifying a bit, their view is that $p$ is a reason to $\phi$ if and only if there is a good pattern of reasoning from fitting responses towards $\phi$-ing, which includes the belief that $p$ as a premise response. One natural way (though not McHugh and Way's own way) of turning this into an account of the weight of reasons is by saying that $p$ is a weightier reason to $\phi$ than the fact that $q$ just in case it would be better
} 
This suggests that the reason why both $\mathrm{R}=\mathrm{EO}$ and $\mathrm{R}=\mathrm{PGR}$ are informative is that they manage, as I would like to call it, to naturalize the contributory. What do I mean by this? Not, of course, that they amount to naturalistic reductions of the notion of a reason. Since the explanans contains a normative notion in both cases, it is clear that the accounts are not fully naturalistic. ${ }^{14}$ Rather, what both accounts do is to naturalize the contributory element implicit in the notion of a reason, insofar as the only contributory notion in the explanans is a fully non-normative one ('evidence' in the one case, 'motivation' in the other). ${ }^{15}$

Moreover, this seems to be among the features that make these accounts so attractive. At the outset, we wonder what the contributory normative force of reasons consists in. We then explain the notion of a reason in terms of a contributory

\begin{abstract}
Footnote 13 (continued)
to reason from $p$ towards $\phi$-ing than from $q$. Since good reasoning is here understood as fittingnesspreserving reasoning, we could understand 'better reasoning' as reasoning that is 'more fittingness-preserving', where this is cashed out in modal terms: a pattern of reasoning is more fittingness-preserving than another just in case it preserves fittingness in a wider range of possible worlds. (For example, the pattern 'An extremely reliable judge tells me that $p$; hence, $p$ ' preserves fittingness in a wider range of possible worlds than the pattern 'A moderately reliable judge tells me that $p$; hence, $p$ ', which is why the testimony of an extremely reliable judge is a weightier reason than the testimony of a moderately reliable judge.).
\end{abstract}

This would amount to a fully non-normative account of the weight of reasons if either (i) the notion of fittingness itself turns out to be reducible to something non-normative, or (ii) at least the notion of fittingness-preservation is non-normative in the relevant sense. (ii) might seem particularly promising, since the notion is a conditional one-to say that a pattern preserves fittingness is to say that if the premise responses are fitting, then so is the conclusion response-, and it is at least arguable whether such conditional notions count as genuinely normative. (After all, you might affirm claims about fittingness-preservation without believing that anything actually is fitting.) Moreover, even if 'fittingness-preserving' is a normative notion, the notion that does the real explanatory work (viz.,'more fittingness-preserving') might still give us a non-normative account of weight in the relevant sense. This is because, once we know all the 'overall' truths about which patterns preserve fittingness, we can determine the weight of reasons simply by looking at the range of circumstances in which they do so. 'Fittingness-preservation' differs in this way from a notion like 'value': even if you knew, for each thing in the world, whether it was valuable or not, you would still need additional normative knowledge to know how valuable it is, but if you knew, for each pattern of reasoning, whether it preserved fittingness or not, you would immediately be in a position to know by how much, without adding any further normative knowledge into the mix. Needless to say, settling these issues would require us to address a number of difficult questions, e.g. about how exactly to understand the notion of fittingness-preservation and what it is that makes a notion normative. Therefore, we cannot settle at this point whether McHugh and Way's version of R=PGR manages to 'naturalize the contributory' (as I call it below), though I have made a tentative suggestion for how such a case could be made.

14 Of course, it might be possible to turn these views into fully naturalistic accounts by giving further naturalistic reductions of notions like 'ought' or 'good reasoning', but we can leave this possibility entirely open here.

15 One caveat about the term 'naturalizing': I do not want to commit to the claim that non-normative notions like 'evidence' or 'motivation' are naturalistic in a strong sense of that term, where 'naturalistic' means something like 'being amenable to natural-scientific explanation'. I think there is also a familiar, weaker sense, in which these notions count as naturalistic whether or not they can be understood in natural-scientific terms, but we need not quarrel about the term 'naturalism' here. What matters for my argument is that these are non-normative notions, and for lack of a better word, I will continue to use the term 'naturalizing' in this context. 
non-normative notion like 'evidence' or 'motivation' and an overall normative notion like 'ought' or 'good reasoning'. This tells us, as it were, what one needs to 'put into the mix', metaphysically speaking, to get the contributory normative notion of a reason. What $\mathrm{R}=\mathrm{EO}$ and $\mathrm{R}=\mathrm{PGR}$ enable us to do is to understand the contributory ingredient of this mix in wholly non-normative terms, and this is what makes these accounts paradigmatically informative as far as the contributory nature of normative reasons specifically is concerned.

Against this background, we can now explain the sense in which $\mathrm{R}=\mathrm{ERR}$ seems uninformative. The account proceeds in terms of two central notions: 'evidence' and 'rightness in a respect'. As we have seen, the notion of evidence is a contributory non-normative notion. The notion of 'rightness in a respect' is a normative notion, but it is also a contributory notion, because to say that $\phi$-ing is right in a respect is not to say anything about its overall normative status. Hence, $\mathrm{R}=\mathrm{ERR}$ analyzes a contributory normative notion ('reason') in terms of a contributory non-normative notion ('evidence') and another contributory normative notion ('rightness in a respect').

This means, in short, that $\mathrm{R}=\mathrm{ERR}$ fails to naturalize the contributory. Unlike $\mathrm{R}=\mathrm{EO}$, which explains the contributory force of reasons in terms of the non-normative contribution that evidence makes to the overall epistemic probability of an 'ought' proposition, and R=PGR, which explains the contributory force of reasons in terms of the non-normative contribution that specific motivational factors make to the overall response of a well-reasoning agent, $\mathrm{R}=\mathrm{ERR}$ only replaces one contributory normative notion by another, so far unanalyzed notion of the same status. Unless we now provide an account of the contributory nature of this notion, we have not made much progress in understanding contributory normative force as such. $\mathrm{R}=\mathrm{ERR}$ in this way lacks one of the features that makes $\mathrm{R}=\mathrm{EO}$ and $\mathrm{R}=\mathrm{PGR}$ informative and, on that account, particularly appealing.

Of course, this last criticism need not be a fatal blow against $\mathrm{R}=\mathrm{ERR}$. Perhaps there are other things that $\mathrm{R}=\mathrm{ERR}$ does explain in illuminating ways; what is more, being informative (either in the way I just made precise, or more generally) is not the only relevant desideratum in the assessment of reductive accounts of reasons. (Note, however, that if my argument from the previous section is correct, $\mathrm{R}=\mathrm{ERR}$ does not do particularly well along the dimension of extensional adequacy, either.) The point remains that failing to naturalize the contributory is an important theoretical defect. In the following section, I explain in more detail why this is so, focusing on the connection between naturalizing the contributory and explanatory power.

Before I do so, I want to complete this section by looking at two other prominent accounts of reasons, both of which are like $\mathrm{R}=\mathrm{ERR}$ in that they fail to naturalize the contributory: (i) John Broome's (e.g. 2018) account of reasons in terms of explanation and 'ought', and (ii) the account of reasons in terms of explanation and value, defended (among others) by Stephen Finlay (2006) and Joseph Raz (1999). ${ }^{16}$ The former fails to naturalize the contributory in a fairly straightforward, the latter in a more interesting, way.

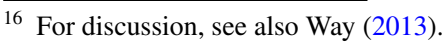


Broome's view is the following:

$(\mathrm{R}=\mathrm{ExO})$ The fact that $p$ is a reason for a person to $\phi$ if and only if $p$ plays the for- $\phi$ role in a weighing explanation of why that person ought to $\phi$, or why that person ought not to $\phi$, or why it is not the case that this person ought to $\phi$ and not the case that this person ought not to $\phi .{ }^{17}$

$\mathrm{R}=\mathrm{ExO}$ proceeds in terms of three central notions: '(weighing) explanation', 'for- $\phi$ role' and 'ought'. The notion of 'ought' is, again, an overall normative notion. The notion of a 'weighing explanation' has an unclear status. On the one hand, the notion of an explanation as such seems to be a non-normative, purely metaphysical notion. To say that ' $p$ explains $q$ ' is not as such to make a normative claim, and our general understanding of what it means to explain something seems to be independent of any normative presuppositions. Arguably, we understand in wholly non-normative terms what it would mean to say, for instance, that the various parts of the theory of relativity together explain the impossibility of time-travel. What is more, there is at least one clearly non-normative sense of 'weighing explanation' in particular, viz. the sense in which weights on a scale explain why a scale tips. On the other hand, Broome (2018: p. 52) himself says that the analogy with mechanical weighing is "not perfect," and so that the sense in which we give weighing explanations of normative facts might well be importantly different from the sense in which we give weighing explanations elsewhere - in particular, by being irreducibly normative.

Be that as it may, the notion of a 'for- $\phi$ role' is clearly a normative notion, and it is also clearly a contributory notion. Hence, $\mathrm{R}=\mathrm{ExO}$ analyzes a contributory normative notion ('reason') partly in terms of another contributory normative notion ('for- $\phi$ role'). Like $\mathrm{R}=\mathrm{ERR}$, it thereby fails to naturalize the contributory.

A common criticism of Broome's view is that it is actually circular, either because the notion of a 'for- $\phi$ role' (cf. Brunero 2013) or the notion of a weighing explanation (cf. Gregory 2016) already presupposes the notion of a reason. Note that, if this is right, it would simply amount to a special case of the problem raised here (viz., that the account fails to naturalize the contributory). In Broome's case, this other contributory normative notion would simply turn out to be identical to the notion of a reason, or at least to a notion that is partly defined in terms of reasons. The important point for our purposes is that one could criticize $\mathrm{R}=\mathrm{ExO}$ for failing to naturalize the contributory, even if these criticisms failed and Broome was right to think that the account is not circular.

Finally, Raz (1999) and Finlay (2006) endorse:

$(\mathrm{R}=\mathrm{ExV})$ The fact that $p$ is a reason for a person to $\phi$ if and only if $p$ explains why it would be good in some respect and to some degree if that person $\phi$-ed.

\footnotetext{
17 Strictly speaking, this is just Broome's account of pro tanto reasons. He has a different account of what he calls perfect reasons, and his account of a normative reason is the account of something that is either a perfect or a pro tanto reason. One might be unhappy with such a disjunctive account of reasons on independent grounds, but since our topic is anyway just the notion of a reason in the contributory (i.e., pro tanto) sense, we can leave these complications aside. For discussion, see, e.g., Brunero (2013).
} 
$\mathrm{R}=\mathrm{ExV}$ proceeds in terms of two central notions: 'explanation' and 'good in some respect and to some degree'. Again, the notion of explanation as such is, arguably, a non-normative notion. The notion of goodness as such is an overall normative notion. However, $\mathrm{R}=\mathrm{ExV}$ does not simply appeal to the notion of goodness as such, and for good reason: one can have a normative reason to $\phi$ even in cases where $\phi$-ing is not good, and so (because 'explanation' is factive) there is nothing that explains why $\phi$-ing is good. The value-based account avoids this problem by saying that, in such cases, the reason still explains why it would be good in at least some respect and to at least some degree if the person $\phi$-ed. The notion of goodness in some respect and to some degree is clearly a contributory normative notion, though. This means that $\mathrm{R}=\mathrm{ExV}$ analyzes a contributory normative notion ('reason') partly in terms of another contributory normative notion ('good in some respect and to some degree'). Like $\mathrm{R}=\mathrm{ERR}$ and $\mathrm{R}=\mathrm{ExO}$, it thereby fails to naturalize the contributory.

Having said that, putting things in just these terms also leaves out something important. Although both 'reason' and 'good in some respect and to some degree' are both contributory normative notions, they are normative notions of a very different kind: the former is deontic, while the latter is evaluative. This has two implications.

First, it means that while $\mathrm{R}=\mathrm{ExV}$ fails to naturalize the contributory, it still allows us to understand the nature of one kind of normative contribution-viz., the way in which reasons contribute to overall deontic statuses like 'ought' - in terms of the nature of a different kind of normative contribution-viz., the way in which goodness in various respects and to various degree contributes to overall evaluative statuses like '(plain) good' or 'best'. It is consistent with anything that I have said so far that this is more informative than the attempt to understand the contributory nature of one deontic notion in terms of the contributory nature of another deontic notion, since it at least bridges the deontic-evaluative gap.

Second, the account still remains less informative than $\mathrm{R}=\mathrm{EO}$ or $\mathrm{R}=\mathrm{PGR}$, since it runs into a variant of the same intuitive problem that undermines $R=E R R$, and which I will flesh out in more detail below. Again, the intuitive problem is that the very same questions arise about the nature of this other contributory notion that already arise about the notion of a reason itself. Reducing deontic to evaluative contributions might well be progress, but at the end of the day, the nature of the latter is as much in need of explanation as the former. In particular, since deontic and evaluative notions are both normative, the nature of normative contribution as such would remain unexplained. This contrasts sharply with accounts that explain normative contributions in terms of evidential or motivational contributions, which are non-normative phenomena on wich we have an entirely independent grip.

The example of $\mathrm{R}=\mathrm{ExV}$ thus yields an important upshot. While it is consistent with my argument so far that some accounts which fail to naturalize the contributory are still more informative than $\mathrm{R}=\mathrm{ERR}$, they remain less informative than an account of reasons could be, and less informative than we intuitively want such an account to be. The next section puts some more flesh on this intuition. 


\section{What do we want from an account of reasons?}

In the previous section, I suggested that $R=E R R$ seems uninformative in some interesting sense even if it is not strictly speaking circular, and I explained how this intuitive verdict leads to the notion of naturalizing the contributory. This section elaborates in more detail why that feature is an important desideratum for accounts of reasons. The discussion still uses $\mathrm{R}=\mathrm{ERR}$ as our primary example, but the resulting lesson will be relevant quite generally and apply to accounts of reasons as such.

Our question is: Why exactly does the fact that an account (or at least a reductive account) of reasons is uninformative in the sense I described make it defective? In the case of $\mathrm{R}=\mathrm{ERR}$, after all, I have already explained that it is not circular, and so it clearly has some content: at least, it tells us how two contributory normative notions relate to each other, which might itself be an interesting result. As Whiting (2205) puts it, an "account might be illuminating or informative insofar as it traces significant connections among the relevant concepts, connections which are not otherwise apparent." Consequently, one might think that calling such accounts uninformative is unfair and misleading. The rest of this section addresses this concern. It will thereby help us to understand better both the nature of my objection against $\mathrm{R}=\mathrm{ERR}$ and, more generally, which aims an account of normative reasons is meant to serve in the first place.

The first thing to note is that it seems plausible on quite general theoretical grounds that a successful reductive account of reasons naturalizes the contributory (or at least that this would be a major advantage). Those who want an account of normative reasons - or, at least, those who want a reductive account - think that several features of reasons are worthy of explanation. Some of these features concern the normativity of reasons. It is an open question whether any of the accounts discussed here could be turned into a fully non-normative reduction of the normativity of reasons, and whether or not such a theoretical maneuver would be desirable in the first place. These are not our questions here.

Another feature of reasons worthy of explanation is their specifically contributory nature among the central normative notions. What distinguishes the notion of a reason from other familiar notions like 'ought', 'right', 'duty', 'permissibility','goodness', 'fittingness' or 'correctness' is that it does not concern the overall normative status of an action or attitude, but merely one aspect that contributes to this status. Even if 'reason' is not unique in this regard (we have already agreed that 'right in a respect' is a different, but equally contributory, normative notion), there is clearly an important contrast here, and one would like to have an account of that contrast. To provide such an account requires us to explain what it means in particular for a consideration to contribute to the obtaining of some overall normative status or other, or as Dancy (2004, Ch. 2) helpfully put it, to "catch the contributory."

A legitimate question at this point, which has already been implicit in the previous section, is why such an account needs to explain the contributory nature of reasons in non-normative terms. Would it not be enough if it simply explained this nature in terms of something that we have an independent grip on? Critics of my 
thesis might insist that such an account would not give us less information than one that naturalizes the contributory; it would merely give us different information. ${ }^{18}$

I think that this question can be answered. First, R =ERR itself illustrates the difference in question. I argued earlier that Whiting's account does just what these critics imagine: far from being circular, it explains the contributory nature of reasons in terms of another contributory normative notion that we have an independent grip on. Still, there seems to be something deeply unsatisfying about the informativeness of the account, because it merely replaces one contributory normative notion by another contributory normative notion, thereby leaving the nature of normative contribution as such as much in need of explanation as before (and if there was an effective way of illuminating the contributory nature of this second notion, one might well wonder why it cannot be used to illuminate the contributory nature of reasons right away). If we accept this intuitive verdict about $\mathrm{R}=\mathrm{ERR}$, it follows that an account can be insufficiently informative even it it succeeds in explaining the notion of a reason in terms of something that we have an independent grip on. In particular, it might still leave some of the most important questions unanswered, as we will see in more detail below.

Second, it is not true that accounts which fail to naturalize the contributory merely give us different information. Even if we grant-implausibly, as I just suggested - that the former could successfully illuminate the contributory nature of reasons, they would not thereby illuminate the nature of contributory normative force just as such. This is because, by definition, they rely on at least one contributory normative notion (like 'right in a respect', 'for- $\phi$ role', or 'good in some respect and to some degree') as an unexplained primitive. And so, at the end of the day, we still have not answered the question of what makes a normative notion a contributory one; we have merely replaced the notion about which this question is asked. The point is not to deny that we have made some progress; the point is just that naturalizing the contributory makes more progress, and that this is one reason (albeit not necessarily a decisive one) to prefer accounts with this feature. The present objection fails, because naturalizing the contributory does not merely give us different, but more information, about the normative landscape.

I now return to the claim that, if an account fails to naturalize the contributory, it fails to explain some of the features that make the notion of a reason especially interesting or even puzzling. Whiting (2191f) himself accepts the underlying desideratum: "One motivation for developing an account of reasons is that they seem to play a number of significant roles in our ethical lives... It would be good to have an account of reasons which explains or reveals what makes them apt to play these roles." Similarly, when defending their own account of normative reasons, McHugh and Way (2016: 577) tell us that "accounts of a property $F$ in terms of another property G" are attractive to the extent that they "promise straightforward explanations of features of F."

The problem with $\mathrm{R}=\mathrm{ERR}$ is that, because it fails to naturalize the contributory, it also fails to address certain very specific explanatory concerns that a reductive

\footnotetext{
${ }_{18} \mathrm{I}$ am indebted to an anonymous referee for pressing me on this point.
} 
account of normative reasons should be able to address. In the remainder of this paper, let me illustrate this with two examples.

A first desideratum is to explain why people care about reasons in ordinary contexts of deliberation and advice. Whiting (2199) himself acknowledges this and claims that $\mathrm{R}=\mathrm{ERR}$ readily meets this desideratum. On his view, people care about their reasons because reasons are evidence of respects in which their responses are right, and they care about respects in which their responses are right.

This explanation is incomplete, however, for we can now ask why people care about respects of rightness. Presumably, what people ultimately care about is the rightness of their responses. This would explain why they care about the rightness of their response in a particular respect only if there is some story to tell about how the various other respects in which a certain response is right (or wrong) combine to yield an overall verdict about the rightness of the response as such. But now this does not look very different from the way in which various reasons for and against a response combine to yield a verdict about the overall normative status of that response. It seems that without an independent account that explains how respects of rightness relate to rightness proper, we have not made much progress. (And if we had such an account, the question would be why some version of it cannot be applied directly to the notion of a reason, and so why bringing in the notion of rightness in a respect is not just an unnecessary detour.) The source of the problem is, of course, that $\mathrm{R}=\mathrm{ERR}$ bottoms out in a contributory normative notion that is itself unanalyzed, and whose connections to the relevant overall notion are left unexplained. ${ }^{19}$

A second, and particularly central, desideratum for an account of reasons is to explain the weight of reasons. Again, Whiting (2199f) accepts this desideratum and offers the following proposal: First, he claims that actions can be more or less wrong. For example, killing someone is more wrong than breaking a promise. Second, he suggests that "the weight of a reason is a function of its weight as evidence and the degree of wrongness" (2200). For example, suppose you know that $\phi$-ing kills someone and that $\psi$-ing breaks a promise. The idea is that this gives you a stronger reason against $\phi$-ing than against $\psi$-ing, because while you know of a respect in which $\phi$-ing is very wrong, you only know of a respect in which $\psi$-ing is moderately wrong.

One problem with this proposal is that it relies on the controversial idea that wrongness comes in degrees. While it is easy to understand what it means for a response to be worse than another, or for it to violate more duties than another, it is not exactly clear what it would mean for an action to be more wrong than another. ${ }^{20}$

\footnotetext{
19 Similarly, we can add, in the case of $\mathrm{R}=\mathrm{ExO}$ and $\mathrm{R}=\mathrm{ExV}$ : without an independent account of how 'for- $\phi$ roles' or respects and degrees of goodness relate to the overall, it is unclear why people care about these things; yet such an account of the contributory in terms of the overall is what we were looking for in the case of reasons to begin with.

20 Another problem, as Whiting (2200) himself notes, is that this proposal applies only to requiring reasons (which are both evidence that it is right to $\phi$ and evidence that it is wrong not to $\phi$ ), but not to justifying reasons (which are merely evidence that it is right to $\phi$ ). Presumably, this is because the idea that actions can be more or less right is even less straightforward than the idea that actions can be more or less wrong. I leave this problem aside here.
} 
Hence, the proposal inherits all the controversy surrounding the idea that wrongness is a gradable notion. Let us grant for the sake of the argument, though, that wrongness in fact comes in degrees. Still, problems remain, which relate directly to the issue of how informative $\mathrm{R}=\mathrm{ERR}$ is.

First, recall that a respect in which it is wrong to $\phi$ is a fact that makes it wrong to $\phi$ in some way or regard. If wrongness comes in degrees, Whiting's proposal entails that there are facts which make it very wrong to $\phi$ in some way or regard, whereas others only make it moderately wrong to $\phi$ in this way or regard. But this just means that respects of wrongness themselves come with individual weights, in which case the assignment and interaction of individual weights in the case of respects of wrongness looks just as much in need of explanation as the assignment and interaction of individual weights in the case of reasons. ${ }^{21}$ Just like we want to know, say, how a very weighty reason not to $\phi$ compares with the conjunction of several moderately weighty reasons not to $\phi$, we now want to know, say, how a very weighty respect in which $\phi$-ing is wrong compares with the conjunction of several moderately weighty respects in which $\phi$-ing is wrong. Questions about the weight of reasons are thus merely replaced by questions about the weight of respects of wrongness.

Second, and putting the notion of rightness in a respect to one side, a more general problem with Whiting's proposal is that it tries to explain the gradability of normative reasons partly in terms of the gradability of the overall normative notion of wrongness. Even if we accept the details of the proposal, we should again wonder how much progress has been made, absent an explanation of what makes it the case that an overall status like wrongness comes in degrees. Again, compare how views that naturalize the contributory fare much better in this regard: for example, $\mathrm{R}=\mathrm{EO}$ gives a straightforward account of the weight of reasons in terms of their weight as evidence for an 'ought' proposition, where this can be cashed out in fully non-normative terms. It is only because $\mathrm{R}=\mathrm{ERR}$ analyzes reasons both in terms of evidence and another contributory normative notion that it cannot avail itself of a similarly satisfactory explanation.

These examples illustrate how accounts of reasons that fail to naturalize the contributory inevitably fail to address certain key explanatory concerns that motivate the very project of understanding the notion of a reason in other terms. This supports a more general lesson: one important desideratum for any account of normative reasons (or at least for any reductive account) is that they naturalize the contributory, in the way that views like $\mathrm{R}=\mathrm{EO}$ or $\mathrm{R}=\mathrm{PGR}$ do. It is only then that they satisfy our pre-theoretical concern with understanding the specifically contributory nature of normative reasons, and it is only then that the resulting account will be powerful enough to explain some of their most central features.

Of course, none of this settles the more general debate between reductivists and primitivists about reasons. We simply have not shown that even the most

\footnotetext{
${ }^{21}$ Similarly, we can add, in the case of $\mathrm{R}=\mathrm{ExO}$ and $\mathrm{R}=\mathrm{ExV}$ : they, too, do not really explain the weight of reasons unless there is an independent account of the weight of 'for- $\phi$ roles' or respects and degrees of goodness.
} 
explanatorily powerful reductive accounts, including those that successfully naturalize the contributory, are preferable to a primitivist one, since the reductive accounts might come with other serious defects. But one thing seems clear already at this point: if there is any good reason to favor reductivism, it will have to do with its greater explanatory power. Since the ability to naturalize the contributory increases explanatory power, reductivists who want to tackle the primitivist head-on have a good reason to go in for corresponding versions of reductivism. To the extent that we want reductive accounts because of their explanatory virtues, we need reductive accounts that naturalize the contributory.

\section{Conclusion}

In this paper, I have pursued two different, but complementary, aims. First, I critically discussed Daniel Whiting's recent proposal that a reason to $\phi$ is evidence of a respect in which it is right to $\phi$. This proposal merits discussion mainly because it promises to retain the central virtues of evidential accounts like $\mathrm{R}=\mathrm{EO}$ while avoiding some of the more compelling counterexamples to such accounts, including counterexamples based on counter-evidential and redundant reasons. However, I then argued that $\mathrm{R}=\mathrm{ERR}$ is also not without its problems. For one thing, it runs into a modified version of Eva Schmidt's counterexample to $\mathrm{R}=\mathrm{EO}$ based on instrumental reasons. In the relevant case, $\mathrm{R}=\mathrm{ERR}$ mistakenly predicts that the fact that one ought to take a necessary means to an end is a reason to realize that end, while in fact the explanation should go in the other direction. For another thing, and although I granted that $\mathrm{R}=\mathrm{ERR}$ is not circular, it is still in an important sense uninformative.

The question 'in what sense exactly?' then lead over to a more general discussion of the criteria of adequacy for reductive accounts of reasons. In particular, I used $\mathrm{R}=\mathrm{ERR}$ to illustrate how important it is for such accounts to naturalize the contributory. Unlike views like $\mathrm{R}=\mathrm{EO}$ or $\mathrm{R}=\mathrm{PGR}, \mathrm{R}=\mathrm{ERR}$ explains the specifically contributory nature of normative reasons partly in terms of the notion of rightness in a respect, which is itself normative and contributory. This makes it structurally less appealing than views which explain this contributory nature in fully non-normative terms and significantly decreases its explanatory power.

Of course, the fact that a view is in this sense uninformative need not by itself be a decisive criticism, because it might offer important theoretical benefits elsewhere. (If my claims about cases involving instrumental reasons are right, though, $\mathrm{R}=\mathrm{ERR}$ does not do particularly well along the dimension of extensional adequacy, either). That being said, the ability to naturalize the contributory is at least one important desideratum for reductive accounts of reasons. In particular, those who favor reductive over primitivist accounts because of their greater explanatory power should prefer those accounts that naturalize the contributory.

More generally, and irrespective of how the notion bears on $\mathrm{R}=\mathrm{ERR}$ specifically, I take it that the notion of naturalizing the contributory is a helpful notion to keep in mind when thinking about the project of understanding the notion of a reason in other terms. 
Acknowledgments For their encouragement and extremely helpful suggestions on earlier versions of this article, I am grateful to Marcel Jahn, Thomas Schmidt, David Streit, Daniel Whiting and two anonymous reviewers for Synthese. Work on this article has been supported by the German Academic Scholarship Foundation.

Funding Open Access funding enabled and organized by Projekt DEAL. Work on this article has been supported by the German Academic Scholarship Foundation.

Conflict of interest The author declare that he has no conflict of interest.

Open Access This article is licensed under a Creative Commons Attribution 4.0 International License, which permits use, sharing, adaptation, distribution and reproduction in any medium or format, as long as you give appropriate credit to the original author(s) and the source, provide a link to the Creative Commons licence, and indicate if changes were made. The images or other third party material in this article are included in the article's Creative Commons licence, unless indicated otherwise in a credit line to the material. If material is not included in the article's Creative Commons licence and your intended use is not permitted by statutory regulation or exceeds the permitted use, you will need to obtain permission directly from the copyright holder. To view a copy of this licence, visit http://creativecommons.org/licen ses/by/4.0\%.

\section{References}

Asarnow, S. (2016). Rational internalism. Ethics, 127(1), 147-178.

Asarnow, S. (2017). The reasoning view and defeasible practical reasoning. Philosophy \& Phenomenological Research, 95(3), 614-636.

Broome, J. (2004). Reasons. In R. J. Wallace, M. Smith, S. Scheffler, \& P. Pettit (Eds.), Reason and value: Themes from the moral philosophy of Joseph Raz (pp. 28-55). Oxford: Oxford University Press.

Broome, J. (2008). Reply to Southwood, Kearns and Star, and Cullity. Ethics, 119(1), 96-108.

Broome, J. (2013). Rationality through reasoning. Oxford: Wiley Blackwell.

Broome, J. (2015). Reasons versus ought. Philosophical Issues, A Supplement to Noûs, 25(1), 80-97.

Broome, J. (2018). Reasons fundamentalism and what is wrong with it. In Daniel Star (Ed.), The Oxford handbook of reasons and normativity (pp. 297-318). Oxford: Oxford University Press.

Brunero, J. (2009). Reasons and evidence one ought. Ethics, 119(3), 538-545.

Brunero, J. (2013). Reasons as explanations. Philosophical Studies, 165(3), 805-824.

Brunero, J. (2018). Reasons, evidence and explanations. In D. Star (Ed.), The Oxford handbook of reasons and normativity (pp. 321-341). Oxford: Oxford University Press.

Chappell, R. (2012). Fittingness: The sole normative primitive. Philosophical Quarterly, 62(249), 684-704.

Dancy, J. (2004). Ethics without principles. Oxford: Oxford University Press.

Finlay, S. (2006). The reasons that matter. Australasian Journal of Philosophy, 84(1), 1-20.

Finlay, S. (2012). Explaining reasons. DeutschesJahrbuchfürPhilosophie, 4, 112-126.

Finlay, S. (2014). Confusion of tongues: A theory of normative language. Oxford: Oxford University Press.

Fumerton, R. (2001). Epistemic justification and normativity. In M. Steup (Ed.), Knowledge, truth, and duty. Essays on epistemic justification, responsibility and virtue (pp. 49-60). Oxford: Oxford University Press.

Gregory, A. (2016). Normative reasons as good bases. Philosophical Studies, 173(9), 2291-2310.

Hofmann, F. (forthcoming). Is evidence normative? Philosophia.

Hieronymi, P. (2005). The wrong kind of reason. Journal of Philosophy, 102(9), 437-457.

Hieronymi, P. (forthcoming). Reasoning First. In: Chang, R., \& Sylvan, K. (eds.) The Routledge Handbook of Practical Reasons, New York, NY, accessed online, https://philpapers.org/archive/HIERF-2. pdf $>$.

Kearns, S., \& Star, D. (2008). Reasons: Explanations or evidence? Ethics, 119(1), 31-56. 
Kearns, S., \& Star, D. (2009). Reasons as evidence. In Russ Shafer-Landau (Ed.), Oxford studies in metaethics (Vol. 4, pp. 215-42). Oxford: Oxford University Press.

Kearns, S., \& Star, D. (2011). On goodadvice: A reply to McNaughton and Rawling. Analysis, 71(3), 506-508.

Kearns, S., \& Star, D. (2013a). Weighing reasons. Journal of Moral Philosophy, 10(1), 70-86.

Kearns, S., \& Star, D. (2013b). Reasons, facts-about-evidence, and indirect evidence. Analytic Philosophy, 54(2), 237-243.

Kearns, S., \& Star, D. (2015). Weighing reasons. In I. Hirose \& A. Reisner (Eds.), Weighing and reasoning: A Festschrift for John Broome (pp. 232-251). Oxford: Oxford University Press.

Kelly, T. (2007). Evidence and normativity: A reply to Leite. Philosophy and Phenomenological Research, 75(2), 465-474.

McHugh, C. (2012). Fitting belief. Proceedings of the Aristotelian Society, 114(2-2), 167-187.

McHugh, C., \& Way, J. (2016). Fittingness first. Ethics, 126(3), 575-606.

McHugh, C., \& Way, J. (2018a). What is good reasoning? Philosophy and Phenomenological Research, 96(1), 153-174.

McHugh, C., \& Way, J. (2018b). What is reasoning? Mind, 127(505), 167-196.

McKeever, S., \& Ridge, M. (2012). Elusive reasons. In Russ Shafer-Landau (Ed.), Oxford studies in metaethics (Vol. 7, pp. 110-137). Oxford: Oxford University Press.

Paakkunainen, H. (2017). Can there be government house reasons for action? Journal of Ethics and Social Philosophy, 12(1), 56-93.

Parfit, D. (2011). On what matters. Oxford: Oxford University Press.

Raz, J. (1978). Introduction. In J. Raz (Ed.), Practical reasoning (pp. 1-17). Oxford: Oxford University Press.

Raz, J. (1999). Engaging reasons. Oxford: Oxford University Press.

Scanlon, T. (1998). What we owe to each other. Cambridge, MA: The Belknap Press of Harvard University Press.

Scanlon, T. (2014). Being realistic about reasons. Oxford: Oxford University Press.

Schmidt, E. (2018). New trouble for 'Reasons as Evidence': Means that don't justify the ends. Ethics, 127(3), 708-718.

Schroeder, M. (2007). Slaves of the passions. Oxford: Oxford University Press.

Schroeder, M. (2015). Is knowledge normative? Philosophical Issues, A Supplement to Noûs, Normativity, 25(1), 379-395.

Schroeter, L., \& Schroeter, F. (2009). Reasons as right-makers. Philosophical Explorations, 12(3), 279-296.

Setiya, K. (2007). Reasons without rationalism. Princeton, NJ: Princeton University Press.

Setiya, K. (2014). What is a reason to act? Philosophical Studies, 167(2), 221-235.

Sharadin, N. (2016). Reasons wrong and right. Pacific Philosophical Quarterly, 97(3), 371-399.

Silverstein, M. (2016). Reducing reasons. Journal of Ethics and Social Philosophy, 10(1), 1-22.

Skorupski, J. (2010). The domain of reasons. Oxford: Oxford University Press.

Smith, M. (2018). Three kinds of moral rationalism. In K. Jones \& F. Schroeter (Eds.), The many moral rationalisms (pp. 48-69). Oxford: Oxford University Press.

Star, D. (2011). Two levels of moral thinking. In M. Timmons (Ed.), Oxford studies in normative ethics (Vol. 1, pp. 75-96). Oxford: Oxford University Press.

Star, D. (2015). Knowing better. Oxford: Oxford University Press.

Star, D. (2016). Replies to Cuneo, Driver, and Littlejohn. Philosophy and Phenomenological Research, 93(3), 728-744.

Star, D. (2018). Introduction. In D. Star (Ed.), The Oxford handbook of reasons and normativity (pp. 1-21). Oxford: Oxford University Press.

Thomson, J. J. (2008). Normativity. Chicago: Open Court.

Toulmin, S. (1950). An examination of the place of reason in ethics. Cambridge: Cambridge University Press.

Whiting, D. (2018). Right in some respects: reasons as evidence. Philosophical Studies, 195(9), 2191-2208.

Way, J. (2013). Value and reasons to favor. In R. Shafer (Ed.), Oxford studies in metaethics (Vol. 8, pp. 27-49). Oxford: Oxford University.

Way, J. (2017). Reasons as premises of good reasoning. Pacific Philosophical Quarterly, 98(2), 251-270.

Wodak, D. (2019). Redundant reasons. Australasian Journal of Philosophy, 2, 1-13. 